\title{
Green Synthesis of Decaglycerol Laurates by Lipase-Catalyzed Transesterification of Methyl Laurate with Decaglycerol
}

\author{
Wenyue Wang, ${ }^{1,2}$ Changyao Liu, ${ }^{1}$ Guiju Zhang $\mathbb{D}^{1}{ }^{1}$ Fan Yang, ${ }^{1}$ Xiaoyan Wang, \\ Fangli Chen, ${ }^{1}$ Feifei Zhao, ${ }^{1}$ Shengnan Wang, ${ }^{1}$ and Baocai Xu ${ }^{1}{ }^{1}$ \\ ${ }^{1}$ School of Food and Chemical Engineering, Beijing Key Laboratory of Flavor Chemistry, \\ Beijing Higher Institution Engineering Research Center of Food Additives and Ingredients, \\ Beijing Technology and Business University, No. 11 Fucheng Road, Beijing 100048, China \\ ${ }^{2}$ China Rural Technology Development Center, Beijing 100045, China \\ Correspondence should be addressed to Guiju Zhang; zhangguiju@th.btbu.edu.cn and Baocai Xu; xubaoc@btbu.edu.cn
} Received 16 December 2018; Accepted 11 April 2019; Published 12 June 2019

Academic Editor: Cesar Mateo

Copyright (C) 2019 Wenyue Wang et al. This is an open access article distributed under the Creative Commons Attribution License, which permits unrestricted use, distribution, and reproduction in any medium, provided the original work is properly cited.

\begin{abstract}
Decaglycerol laurates have been widely used as emulsifiers in food, medicine, and cosmetic industries for many years. Currently, they are synthesized using alkaline catalysts under stringent conditions. Here, decaglycerol laurates were prepared through a green lipase-catalyzed process, employing the transesterification of methyl laurate with decaglycerol by the immobilized lipase (Novozym 435). Single-factor experiments and orthogonal test were used for reaction optimization. The optimum conditions were obtained as follows: reaction temperature of $65^{\circ} \mathrm{C}$, a laurate/decaglycerol molar ratio of $2: 1$, an oscillating speed of $180 \mathrm{rpm}$, an enzyme dosage (based on amount of methyl laurate) of $8 \mathrm{wt} . \%$, initial water content (based on the total substrate mass) of $5.0 \mathrm{wt} . \%$, and reaction time of $4.5 \mathrm{~h}$ with $84.4 \%$ conversion of methyl laurate. The transesterification products were identified by electrospray ionization mass spectrometer. In addition, the surface activity of decaglycerol laurates was also characterized, and the surface tension of water was reduced to $33 \mathrm{mN} \cdot \mathrm{m}^{-1}$ at a concentration magnitude of $10^{-5} \mathrm{~g} / \mathrm{mL}$.
\end{abstract}

\section{Introduction}

The polyglycerol fatty acid esters (PGFEs) are efficient emulsifying agents, which are the mixture of many closely related compounds of complex composition [1]. Recently, researchers have shown an increased interest in biodegradable nonionic surfactants due to the growing applications of environmentally benign products. PGFE has been authorized as food additives in the European Union in accordance with Annex II and Annex III to Regulation (EC) No 1333/2008 on food additives.

In 2017, European Food Safety Authority Panel on Food Additives and Nutrient Sources Added to Food provided a scientific opinion reevaluating the safety of PGFE when used as a food additive and concluded that the PGFE was not of safety concern at the reported uses and use levels [2]. In addition to food industry, PGFEs, as additives, have also been widely applied to various fields, such as, cosmetics, medicine, photography, inks, etc [3-6].

PGFE can be synthesized by the esterification of one or more $\mathrm{OH}$ groups of polyglycerol with fatty acids. Also, the transesterification between triglycerides and fatty acid methyl esters is employed for the preparation of PGFE. Currently, PGFEs are conventionally produced by the esterification or transesterification reaction in the presence of alkaline catalysts, e.g.sodium methoxide [7, 8]. Chemical synthesis methods usually suffer from drawbacks such as complex and dangerous purification steps and the formation of chemical waste and by-products. In addition, these procedures require stringent conditions, in particular, high temperatures. Besides involving high energy costs, the high operating temperature results in undesirable odors and coloration, making it unsuitable for the food industry. 
Alternatively, enzymatic method could overcome the abovementioned drawbacks. The enzymatic approach to PGFE synthesis is highly efficient, environmentally friendly, and sustainable with moderate reaction conditions. It has a tendency that the mild enzymatic approach catalyzed by immobilized lipases will replace the traditional chemical methods for PGFE production. The immobilized lipases have many advantages, including easy recyclability and good reusability [9]. The enzymatic esterification of polyglycerol and fatty acids to give PGFE has been carried out using lipase $[10,11]$. Using diglycerol and oleic acid as starting materials, acid conversion of about $90 \%$ and monoester selectivity of $>94 \%$ have been achieved as the best results [12]. However, the PGFE preparations through the transesterification of polyglycerol and fatty acid esters were rarely reported in the literature [13]. Novozym 435 was a very mature commercial lipase originated from Candida antarctica, which was immobilized on a hydrophobic carrier of acrylic resin. It was quite stable over a wide $\mathrm{pH}$ range, especially in the alkaline conditions. Due to its high degree of substrate specificity with respect to both regio- and enantioselectivity, Novozym 435 showed broad application for the resolution of racemic alcohols, amines, acids, and the preparation of optically active compounds from meso substrates.

In the present work, using the versatile and well-known Novozym 435, decaglycerol laurates were synthesized by transesterification of decaglycerol with methyl laurate in organic solvent through an enzymatic process. The effects of several factors, including, reaction time, substrate molar ratio, reaction temperature, enzyme dosage, initial water content, and the rotating speed of oscillator, on the enzymatic processes were evaluated. Single-factor experiments and orthogonal test were both employed to optimize the lipase-catalytic transesterification process.

\section{Experimental Procedures}

2.1. Materials. The immobilized lipase (Novozym 435) was obtained from Novozymes (China) Biotechnology Co., Ltd., and its activity was determined to be $10000 \mathrm{PLU} \cdot \mathrm{g}^{-1}$. Methyl laurate (99\%) was bought from J\&K Scientific Ltd., (Beijing, China). tert-Butanol (>99\%) was purchased from TCI Development Co., Ltd., (Shanghai, China). Decylglycerol was provided by Jinan Dowin Chemical Technology Co., Ltd. (Shandong, China), and its average degree of polymerization was determined to be 9.66. All other chemicals were of analytical grade and used as received.

\subsection{Lipase-Catalytic Production of Decaglycerol Laurates.} The enzymatic syntheses of decaglycerol laurates were carried out in tert-butanol using Novozym 435. The reaction was initiated by adding $0.014 \mathrm{~mol}$ methyl laurate, $0.007 \mathrm{~mol}$ decylglycerol, $0.2 \mathrm{~g}$ enzyme, and $25 \mathrm{~mL}$ tert-butanol in a $50 \mathrm{~mL}$ Erlenmeyer flask with cover. The reaction mixture was oscillated in an IS-RSV1 thermostatic oscillator (Crystal Technology \& Industries, Inc., USA) at $220 \mathrm{rpm}$ and $60^{\circ} \mathrm{C}$ for six hours. Samples were withdrawn at one hour intervals for HPLC analysis.
The effects of reaction time ( $1 \sim 6 \mathrm{~h})$, molar ratio of methyl laurate and decylglycerol $(2: 1,3: 1$ and $5: 1)$, reaction temperature $\left(50 \sim 75^{\circ} \mathrm{C}\right)$, enzyme dosage (1 9 wt.\% of the amount of methyl laurate), oscillating speed (80 220 rpm), and water content $(0.6 \sim 6.3 \mathrm{wt} . \%$ of the total amount of substrates) on the conversion of methyl laurate were investigated.

2.3. Orthogonal Test. A $\mathrm{L}_{9}\left(3^{4}\right)$ orthogonal array (4 factors, 3 levels, 9 tests) was used for optimization of the reaction conditions. Table 1 shows the factors and levels of the orthogonal test, namely, reaction time $(4.5,5.0$, and $5.5 \mathrm{~h})$, rotating speed $(140,160$, and $180 \mathrm{rpm})$, enzyme dosage $(6,7$, and 8 wt.\%), and water content $(3.8,4.4$, and 5.0 wt.\%).

2.4. HPLC Analysis. Quantitative analysis of methyl laurate was conducted on the Agilent 1200 HPLC-RID system (Agilent, United States), equipped with Agilent Eclipse Plus C18 column $(4.6 \times 250 \mathrm{~mm}, 5 \mu \mathrm{m})$. Conditions for product separation on the HPLC were a ACN/acetone $(1: 1, \mathrm{v} / \mathrm{v})$ mobile phase; flow rate of $1 \mathrm{~mL} / \mathrm{min}$; injection volume of $20 \mu \mathrm{L}$, and the column and detector temperature was 35 and $40^{\circ} \mathrm{C}$, respectively.

A series of methyl laurate solutions of different concentrations were analyzed through aforementioned method. The calibration curve of methyl laurate was obtained as $y=47708.0+139361.4 x\left(R^{2}=0.99857\right)$ and used to determine the concentrations of methyl laurate in reaction mixtures. All trials were conducted in triplicate.

2.5. Mass Spectrometry. Mass spectra were acquired on the API 3200 triple-quadrupole mass spectrometer (AB SCIEX, United States) with Turbo $\mathrm{V}^{\mathrm{TM}}$ source and electrospray ionization (ESI) probe operating at positive mode. The mass spectrometer was operated with electrospray voltage $+4500 \mathrm{~V}$ and source temperature of $450^{\circ} \mathrm{C}$. Nitrogen was used as nebulizing gas (GS1), drying gas (GS2), and curtain gas at 55,60 , and 40 units, respectively.

2.6. Measurement of Surface Tension. The equilibrium surface tensions of the aqueous solutions were obtained using a Dataphysics tensiometer DCAT11 (Dataphysics, Germany) by the Wilhelmy plate method. Surfactant solutions were prepared with deionized water. The sample temperature was maintained at $(25 \pm 0.2)^{\circ} \mathrm{C}$. All measurements were replicated at least three times.

\section{Results and Discussion}

3.1. Effect of Reaction Time. The time course profile of transesterification is shown in Figure 1. As expected, the conversion of methyl laurate increased with the increase of reaction time. Finally, the reaction could achieve equilibrium after $6 \mathrm{~h}$ with the methyl laurate of $61 \%$. A plateau region was observed after $5 \mathrm{~h}$, indicating that the reaction had reached equilibrium and the conversion did not further increase. 
TABLE 1: Factors and levels for orthogonal test.

\begin{tabular}{lcccc}
\hline \multirow{2}{*}{ Levels } & \multicolumn{3}{c}{ Factors } \\
& A, reaction time $(\mathrm{h})$ & B, oscillating speed (rpm) & C, enzyme dosage (wt.\%) & D, water content (wt.\%) \\
\hline 1 & 4.5 & 140 & 6 & 3.8 \\
2 & 5.0 & 160 & 7 & 4.4 \\
3 & 5.5 & 180 & 8 & 5.0 \\
\hline
\end{tabular}

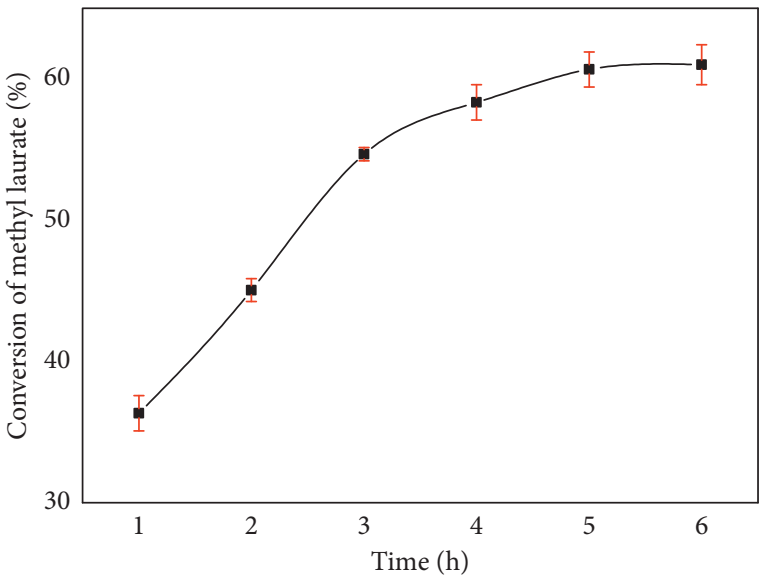

FIGURE 1: Effect of reaction time on lipase-catalyzed transesterification of decylglycerol with methyl laurate.

3.2. Effect of Substrate Molar Ratio. The lipase-catalytic reactions were performed at different molar ratios of methyl laurate and decylglycerol. Figure 2 illustrated the maximum conversion of methyl laurate (59\%) was observed when the ratio between methyl laurate and decylglycerol was $2: 1$. When the molar ratio further increased to $3: 1$ and $5: 1$, the conversion decreased. The result was consistent with the reported enzymatic transesterification of methyl esters and diglycerol in a solvent-free system, indicating that the transesterification reaction favored a high diglycerol to methyl ester ratio [10]. Unfortunately, the conversion of the reaction mixture with methyl laurate/decylglycerol molar ratio lower than $2: 1$ could not be measured because further addition of decylglycerol, the substrate with high-viscosity, only resulted in two immiscible phases.

3.3. Effect of Temperature. The influence of temperature on the transesterification reaction was also determined. In general, industrial productions required elevated reaction temperatures because high temperature could enhance the reaction speed, increase the solubility of both substrate and production, reduce microbial contamination, and even promote the reaction equilibrium moving towards the products. As shown in Figure 3, initially the conversion of methyl laurate increased with increasing temperature, and the highest conversion $(63 \%)$ was obtained at $65^{\circ} \mathrm{C}$. For temperatures higher than $65^{\circ} \mathrm{C}$, the conversion of methyl laurate decreased. Similar results were also reported by Duan et al. for the production of 1,3-diolein via lipase-catalyzed reaction [14]. It is generally considered that enzymes have an "optimal working temperature." For Novozym 435, the

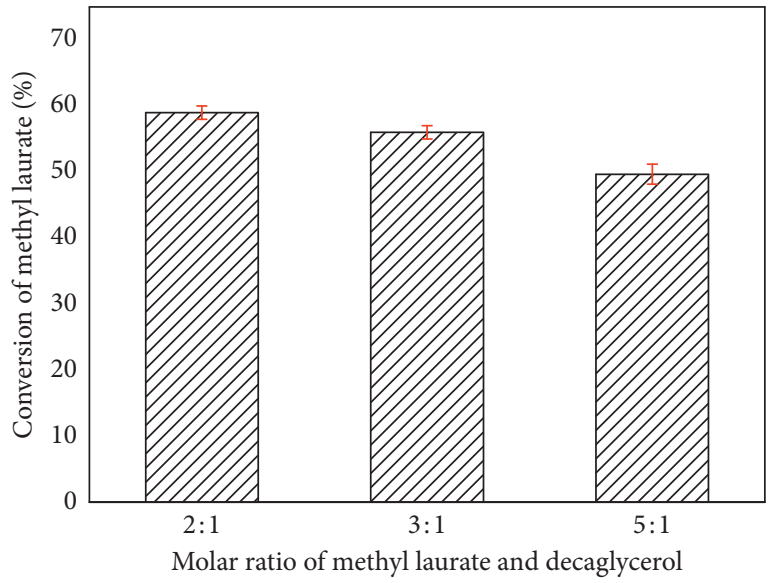

FIgURE 2: Effect of molar ratio on lipase-catalyzed transesterification of decylglycerol with methyl laurate.

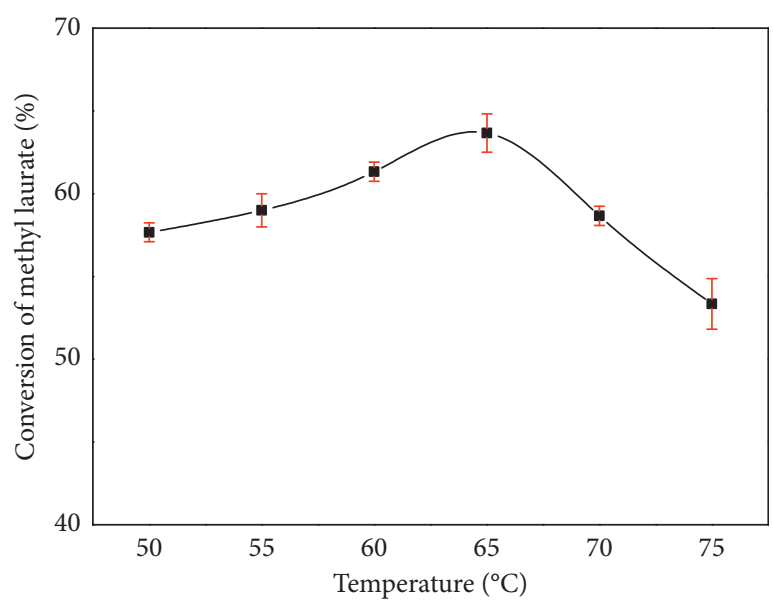

FIgURE 3: Effect of temperature on lipase-catalyzed transesterification of decylglycerol with methyl laurate.

optimal temperature is in the range from 40 to $65^{\circ} \mathrm{C}$ as the temperature could impact the stability of the enzyme via adjusting its secondary and tertiary conformations $[15,16]$.

3.4. Effect of Enzyme Concentration. To investigate the effect of the enzyme concentration on the conversion of methyl laurate, a number of experiments with various enzyme dosage (1 9 wt.\%) were performed. As displayed in Figure 4, the conversion of methyl laurate increased rapidly with lipase concentration increasing in the range of $1 \sim 7 \mathrm{wt} . \%$, which could be due to the increase in the concentration of catalyst causing an increase in the collision frequency with 


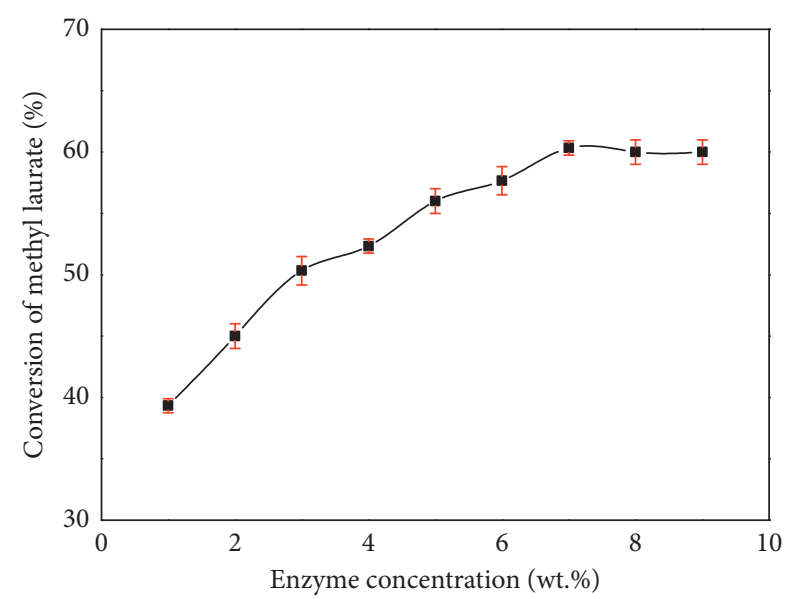

FIGURE 4: Effect of enzyme concentration on lipase-catalyzed transesterification of decylglycerol with methyl laurate.

the reactants [17]. At $7 \mathrm{wt} . \%$, the conversion reached $60 \%$. However, when the enzyme concentration was above $7 \mathrm{wt} . \%$, the conversion hardly changed any more. This phenomenon may be resulted from that the active sites of the enzyme molecules presented in large excess would not be exposed to the substrates as the protein aggregations might occur $[18,19]$. From a cost perspective, an enzyme dosage of $7 \mathrm{wt} . \%$ was considered as an appropriate choice for the transesterification reaction.

3.5. Effect of Oscillating Speed. Experiments were carried out at oscillating speeds between 80 and $220 \mathrm{rpm}$, under the optimum conditions selected based on the above discussions $\left(65^{\circ} \mathrm{C}, 5 \mathrm{~h}\right.$, molar ratio of methyl laurate and decylglycerol $2: 1$, enzyme dosage 7 wt.\%). Figure 5 showed the changes of methyl laurate conversion versus the oscillating speed of the thermostatic oscillator. The conversion of methyl laurate increased firstly and then leveled off when the oscillating speed was higher than $160 \mathrm{rpm}$. This behavior indicated that there was mass transfer dependence because of external diffusion mechanisms below $160 \mathrm{rpm}$. However, the system reached equilibrium, and no mass transfer limitation was detected, at high oscillating speed.

3.6. Effect of Initial Water Content. The presence of water in the initial reaction mixture has been recognized as a crucial factor for maintaining the optimum activity of enzyme. An appropriate amount of water is required to balance the rigidity and thermodynamic stability of the enzyme structure $[20,21]$. In contrast, excessive water causes acyl migration, leading to decrease in product yield [22].

The effect of initial water content on lipase-catalyzed transesterification of decylglycerol with methyl laurate was studied (Figure 6). As initial water content increased, the conversion increased firstly and then decreased with a maximum at $4.4 \mathrm{wt} . \%$. When more than $4.4 \mathrm{wt}$.\% water was added, the conversion of methyl laurate dropped gradually. This may be due to the hydrolysis of methyl laurate in the present of water, generating free fatty acid. Yamane et al.

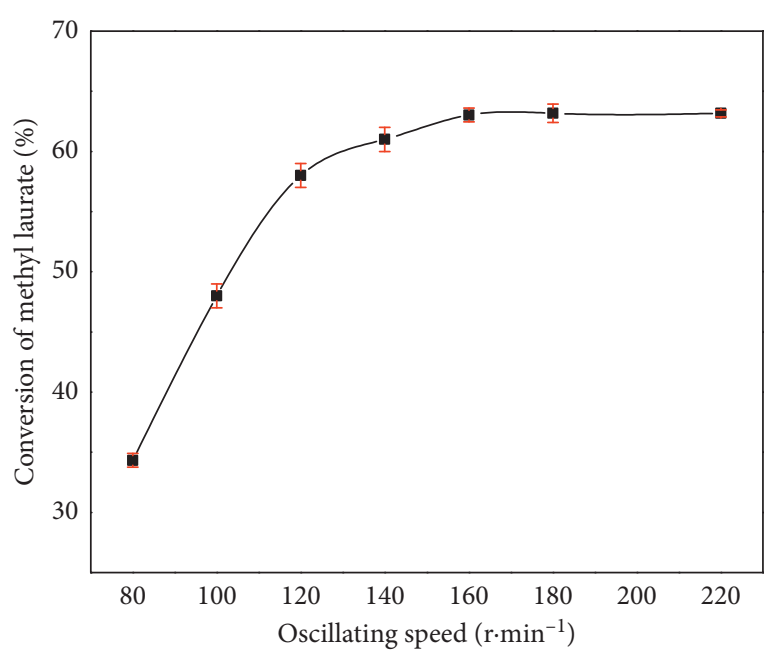

FIGURE 5: Effect of oscillating speed on lipase-catalyzed transesterification of decylglycerol with methyl laurate.

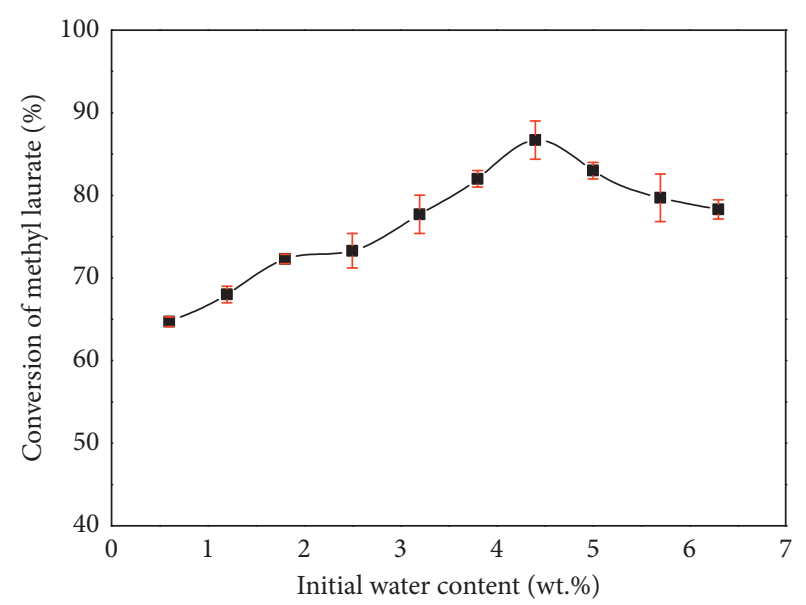

FIgURE 6: Effect of initial water content on lipase-catalyzed transesterification of decylglycerol with methyl laurate.

found that free fatty acid content at equilibrium depended on the water concentration in the glycerol phase [23].

3.7. Orthogonal Test. To achieve maximal conversion of methyl laurate, a three-level four-factor orthogonal test design was employed to optimize the reaction conditions, including, reaction time, oscillating speed, enzyme dosage, and initial water content. The results of orthogonal test are presented in Table 2. The extreme difference analysis was performed according to the average conversions for each level, $k_{i}(i=1,2,3)$, and the range of $k_{i}, R$, listed in Table 2 .

The maximum conversion of methyl laurate was $83.3 \pm 1.5 \%$ (Table 2 (row 4)) although it is not our final best enzymatic conditions. The optimum conditions determined by the orthogonal experiments were as follows: reaction time was $4.5 \mathrm{~h}$; rotating speed $=180 \mathrm{rpm}$; enzyme dosage as $8 \mathrm{wt} . \%$, and water content was $5 \mathrm{wt} . \%$. Through confirmatory test, the highest conversion of methyl laurate was obtained at $84.4 \pm 1.1 \mathrm{wt} . \%$. As demonstrated in Table 3, the analysis of 
TABLE 2: Analysis of $\mathrm{L}_{9}\left(3^{4}\right)$ test results.

\begin{tabular}{|c|c|c|c|c|c|}
\hline \multirow{2}{*}{$\begin{array}{l}\text { Experiment } \\
\text { no. }\end{array}$} & \multicolumn{4}{|c|}{ Factors } & \multirow{2}{*}{$\begin{array}{c}\text { Conversion of } \\
\text { methyl laurate (\%) }\end{array}$} \\
\hline & A, reaction time $(\mathrm{h})$ & B, oscillating speed (rpm) & C, enzyme dosage (wt.\%) & $\mathrm{D}$, water content (wt.\%) & \\
\hline 1 & 4.5 & 140 & 6 & 3.8 & $73.3 \pm 1.5$ \\
\hline 2 & 4.5 & 160 & 7 & 4.4 & $79.7 \pm 2.1$ \\
\hline 3 & 4.5 & 180 & 8 & 5.0 & $81.0 \pm 2.0$ \\
\hline 4 & 5.0 & 140 & 7 & 5.0 & $83.3 \pm 1.5$ \\
\hline 5 & 5.0 & 160 & 8 & 3.8 & $82.7 \pm 1.5$ \\
\hline 6 & 5.0 & 180 & 6 & 4.4 & $78.3 \pm 1.2$ \\
\hline 7 & 5.5 & 140 & 8 & 4.4 & $83.0 \pm 1.0$ \\
\hline 8 & 5.5 & 160 & 6 & 5.0 & $78.3 \pm 2.1$ \\
\hline 9 & 5.5 & 180 & 7 & 3.8 & $82.0 \pm 2.0$ \\
\hline$k_{1}$ & 78.0 & 79.9 & 76.6 & 79.3 & \\
\hline$k_{2}$ & 81.4 & 80.2 & 81.7 & 80.3 & \\
\hline$k_{3}$ & 81.1 & 80.4 & 82.2 & 80.9 & \\
\hline $\mathrm{R}$ & 3.4 & 0.6 & 5.6 & 1.5 & \\
\hline
\end{tabular}

TABLE 3: Variance analysis results.

\begin{tabular}{|c|c|c|c|c|c|}
\hline Variation sources & SS & $\mathrm{df}$ & MS & $\mathrm{F}$ & $P$ \\
\hline A & 64.963 & 2 & 32.481 & 11.244 & 0.001 \\
\hline B & 1.407 & 2 & 0.704 & 0.244 & 0.786 \\
\hline $\mathrm{C}$ & 168.519 & 2 & 84.259 & 29.167 & 0.000 \\
\hline $\mathrm{D}$ & 11.185 & 2 & 5.593 & 1.936 & 0.173 \\
\hline Error & 52.000 & 18 & 2.889 & & \\
\hline
\end{tabular}

variance (ANOVA) was also performed by statistical software SPSS 21.0 (SPSS Inc.). According to the results from both ANOVA and $R$ values, it could be found that the significance of these factors decreased in the order: enzyme dosage $>$ reaction time $>$ water content $>$ rotating speed. Among all the factors, the enzyme dosage had the strongest effect on the conversion of methyl laurate.

\subsection{Characterization of Decaglycerol Laurates}

3.8.1. ESI-MS Analysis. The mass spectra of decaglycerol and decaglycerol laurates were acquired by electrospray ionization in positive mode. A wide range of peaks corresponding to the characteristic ions of decaglycerol and decaglycerol laurates were found in these spectra (Table 4). Decaglycerol was a mixture of polyglycerols with different polymerization degree ranging from $2 \sim 14$, and therefore, the transesterification products of decaglycerol and methyl laurate were also a series of polyglycerol laurates with different polymerization degree as well as esterification degree. The peak signals of polyglycerols and polyglycerol laurates with high polymerization degree were weak, so there may be some compounds with even higher polymerization degree that were not observed in the spectra.

Table 4 displayed that the products were mainly composed of polyglycerol monoesters with polymerization degree ranging from $2 \sim 10$, and a few polyglycerol diesters were observed. This result indicated that the enzymatic transesterification of decaglycerol and methyl laurate in this experiment has excellent monoester selectivity, consistent with our previous results about the lipase-catalytic production of glycerol monolaurate by transesterification of glycerol and methyl laurate [24]. However, the oligoglycerol fatty acid esters enzymatically prepared by the esterification of oligoglycerol (mainly composed of diglycerol, triglycerol, and tetraglycerol) and linoleic acid always give mixtures of monoesters, diesters, triesters, and tetraesters [12].

3.8.2. Surface Tension. Figure 7 showed the surface tension $(\gamma)$ profiles of the aqueous solutions of decaglycerol laurates at $25^{\circ} \mathrm{C}$. It was generally believed that for surfactant solutions, the $\gamma$ value decreased linearly as the logarithm of the surfactant concentration increased to a certain point. And beyond that point, it almost maintained constant, where the air/ solution interface was fully saturated. Therefore, the CMC value was determined by the break point in the curve. However, the CMC of decaglycerol laurates could not be determined precisely because the surface tension changed gradually without clear break point. Such gradual change may be contributed by the complex compositions of decaglycerol laurates [7]. However, decaglycerol laurates decreased the surface tension of water to approximately $33 \mathrm{mN} / \mathrm{m}$ at a concentration magnitude of $10^{-5} \mathrm{~g} / \mathrm{mL}$, showing good surface activities.

\section{Conclusion}

This study demonstrated the biosynthesis of decaglycerol laurates with high monoester selectivity by transesterification using Novozym 435 as catalyst. The enzyme dosage, reaction time, initial water content, and oscillating speed were major factors affecting the conversion of methyl 
TABle 4: Compounds and corresponding $m / z$

\begin{tabular}{|c|c|c|c|c|c|}
\hline Compounds & $m / z\left([\mathrm{M}+\mathrm{Na}]^{+}\right)$ & $m / z\left([\mathrm{M}+\mathrm{K}]^{+}\right)$ & Compounds & $m / z\left([\mathrm{M}+\mathrm{Na}]^{+}\right)$ & $m / z\left([\mathrm{M}+\mathrm{K}]^{+}\right)$ \\
\hline Diglycerol & 189.0 & 205.0 & Diglycerolmonolaurate & 371.1 & 387.0 \\
\hline Triglycerol & 263.0 & 278.9 & Triglycerolmonolaurate & 445.1 & 461.0 \\
\hline Tetraglycerol & 337.0 & 352.9 & Tetraglycerolmonolaurate & 519.0 & 535.0 \\
\hline Pentaglycerol & 411.0 & 426.9 & Pentaglycerolmonolaurate & 593.0 & 608.9 \\
\hline Hexaglycerol & 485.0 & 501.0 & Hexaglycerolmonolaurate & 667.0 & 682.9 \\
\hline Heptaglycerol & 558.9 & 574.9 & Heptaglycerolmonolaurate & 740.9 & 757.0 \\
\hline Octaglycerol & 632.9 & 648.9 & Octaglycerolmonolaurate & 815.0 & 831.1 \\
\hline Polyglycerol-9 & 706.8 & 722.8 & Polyglycerol-9 monolaurate & 889.0 & 905.0 \\
\hline Decaglycerol & 780.9 & 796.8 & Decaglycerolmonolaurate & 962.9 & 978.9 \\
\hline Polyglycerol-11 & - & 870.9 & Diglyceroldilaurate & 553.1 & 569.1 \\
\hline Polyglycerol-12 & - & 944.9 & Triglyceroldilaurate & 627.0 & 643.0 \\
\hline Polyglycerol-13 & - & 1018.9 & Tetraglyceroldilaurate & 701.0 & 717.0 \\
\hline \multirow[t]{3}{*}{ Polyglycerol-14 } & - & 1092.8 & Pentaglyceroldilaurate & 775.2 & 791.1 \\
\hline & & & Hexaglyceryldilaurate & - & 865.1 \\
\hline & & & Heptaglyceroldilaurate & - & 939.0 \\
\hline
\end{tabular}

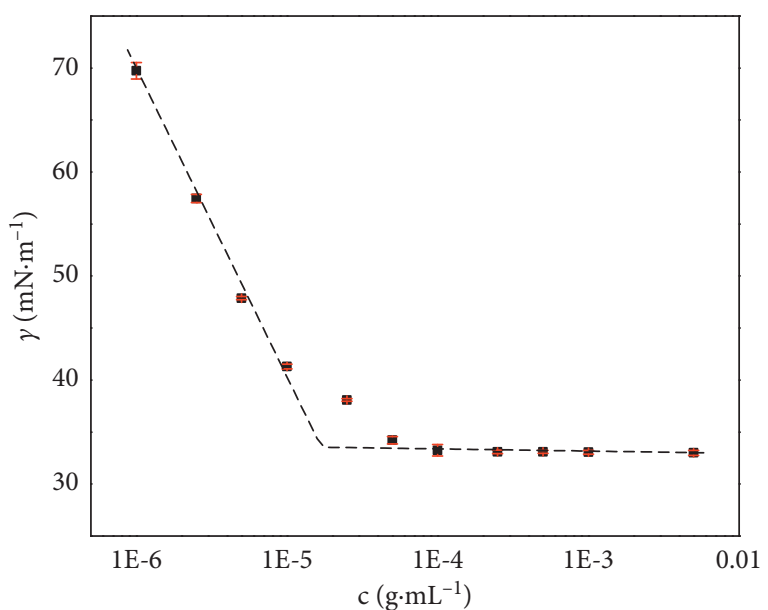

FIGURE 7: Plots of equilibrium surface tensions of aqueous solution of decaglycerol laurates versus mass concentration.

laurate. Under the optimized conditions, $84.4 \%$ conversion of methyl laurate was achieved. The synthesized decaglycerol laurates exhibited good surface activities. This investigated enzymatic production of decaglycerol laurates at mild conditions is considered to be a safe, environmentally friendly, and low-cost method.

\section{Data Availability}

The data used to support the findings of this study are available from the corresponding author upon request.

\section{Conflicts of Interest}

The authors declare that they have no conflicts of interest.

\section{Acknowledgments}

The authors gratefully acknowledge the financial support of Beijing Municipal Science and Technology Project (D17110500190000), the Transformation of Scientific and Technological Achievements-Promotion Plan Project
(PXM2016_014213_000028), and the Science and Technology Program Key Project of Beijing Municipal Commission of Education (KZ201510011010).

\section{References}

[1] Q. Liu, K. Suzuki, S. Kudo et al., "Effect of decaglycerol monooleate on chemiluminescence of human neutrophils," $L u$ minescence the Journal of Biological \& Chemical Luminescence, vol. 14, no. 6, pp. 327-330, 1999.

[2] M. Younes, P. Aggett, F. Aguilar et al., "Re-evaluation of polyglycerol esters of fatty acids (E475) as a food additive," EFSA Journal, vol. 15, no. 12, p. 5089, 2017.

[3] S. Yamaguchi, Z. Kimura, T. Misono et al., "Preparation and properties of nonionic vesicles prepared with polyglycerol fatty acid esters using the supercritical carbon dioxide reverse phase evaporation method," Journal of Oleo Science, vol. 65, no. 3, pp. 201-206, 2016.

[4] C. P. Tan and M. Nakajima, "Effect of polyglycerol esters of fatty acids on physicochemical properties and stability of ?-carotene nanodispersions prepared by emulsification/evaporation method," Journal of the Science of Food and Agriculture, vol. 85, no. 1, pp. 121-126, 2005.

[5] F. F. Sahle, H. Metz, J. Wohlrab, and R. H. H. Neubert, "Polyglycerol fatty acid ester surfactant-based microemulsions for targeted delivery of ceramide AP into the stratum corneum: formulation, characterisation, in vitro release and penetration investigation," European Journal of Pharmaceutics and Biopharmaceutics, vol. 82, no. 1, pp. 139-150, 2012.

[6] N. Khalid, I. Kobayashi, M. A. Neves, K. Uemura, M. Nakajima, and H. Nabetani, "Encapsulation of $\beta$-sitosterol plus $\gamma$-oryzanol in $\mathrm{O} / \mathrm{W}$ emulsions: formulation characteristics and stability evaluation with microchannel emulsification," Food and Bioproducts Processing, vol. 102, pp. 222-232, 2017.

[7] T. Kato, T. Nakamura, M. Yamashita, M. Kawaguchi, T. Kato, and T. Itoh, "Surfactant properties of purified polyglycerol monolaurates," Journal of Surfactants and Detergents, vol. 6, no. 4, pp. 331-337, 2003.

[8] K. S. Shikhaliev, N. V. Stolpovskaya, M. Y. Krysin et al., "Production and emulsifying effect of polyglycerol and fatty acid esters with varying degrees of esterification," Journal of the American Oil Chemists' Society, vol. 93, no. 10, pp. 1429-1440, 2016. 
[9] S. Ortega-Requena, A. Bódalo-Santoyo, J. Bastida-Rodríguez, M. F. Máximo-Martín, M. C. Montiel-Morte, and M. GómezGómez, "Optimized enzymatic synthesis of the food additive polyglycerol polyricinoleate (PGPR) using Novozym 435 in a solvent free system," Biochemical Engineering Journal, vol. 84, pp. 91-97, 2014.

[10] D. Charlemagne and M. D. Legoy, "Enzymatic synthesis of polyglycerol-fatty acid esters in a solvent-free system," Journal of the American Oil Chemists' Society, vol. 72, no. 1, pp. 61-65, 1995.

[11] E. García, F. Ferrari, T. García, M. Martínez, and J. Aracil, "Optimization of the enzymatic esterification of diglycerol and lauric acid," Journal of Surfactants and Detergents, vol. 4, no. 3, pp. 257-262, 2001.

[12] F. Wan, Y. Teng, Y. Wang et al., "Optimization of oligoglycerol fatty acid esters preparation catalyzed by Lipozyme 435," Grasas y Aceites, vol. 66, no. 3, p. e088, 2015.

[13] M. Martínez, R. Oliveros, and J. Aracil, "Synthesis of biosurfactants: enzymatic esterification of diglycerol and oleic acid. 1. Kinetic modeling," Industrial \& Engineering Chemistry Research, vol. 50, no. 11, pp. 6609-6614, 2011.

[14] Z.-Q. Duan, W. Du, and D.-H. Liu, "Improved synthesis of 1,3-diolein by Novozym 435-mediated esterification of monoolein with oleic acid," Journal of Molecular Catalysis B: Enzymatic, vol. 89, no. 3, pp. 1-5, 2013.

[15] B. Zha, Z. Chen, L. Wang, R. Wang, Z. Chen, and L. Zheng, "Production of glycerol monolaurate-enriched monoacylglycerols by lipase-catalyzed glycerolysis from coconut oil," European Journal of Lipid Science and Technology, vol. 116, no. 3, pp. 328-335, 2014

[16] Q. Pan, L. Yang, and X. Meng, "Optimization of enzymatic synthesis of tricaprylin in ionic liquids by response surface methodology," Journal of the American Oil Chemists' Society, vol. 90, no. 4, pp. 501-509, 2013.

[17] N. Majid and B. Cheirsilp, "Optimal conditions for the production of monoacylglycerol from crude palm oil by an enzymatic glycerolysis reaction and recovery of carotenoids from the reaction product," International Journal of Food Science \& Technology, vol. 47, no. 4, pp. 793-800, 2012.

[18] H. Ghamgui, N. Miled, A. Rebaï, M. Karra-chaâbouni, and Y. Gargouri, "Production of mono-olein by immobilized Staphylococcus simulans lipase in a solvent-free system: optimization by response surface methodology," Enzyme and Microbial Technology, vol. 39, no. 4, pp. 717-723, 2006.

[19] M. K. Naik, S. N. Naik, and S. Mohanty, "Enzymatic glycerolysis for conversion of sunflower oil to food based emulsifiers," Catalysis Today, vol. 237, no. 6, pp. 145-149, 2014.

[20] R. Pawongrat, X. Xu, and A. H-Kittikun, "Synthesis of monoacylglycerol rich in polyunsaturated fatty acids from tuna oil with immobilized lipase AK," Food Chemistry, vol. 104, no. 1, pp. 251-258, 2007.

[21] Y. Zhao, J. Liu, L. Deng, F. Wang, and T. Tan, “Optimization of Candida sp. 99-125 lipase catalyzed esterification for synthesis of monoglyceride and diglyceride in solvent-free system," Journal of Molecular Catalysis B: Enzymatic, vol. 72, no. 3-4, pp. 157-162, 2011.

[22] S. Wongsakul, P. Prasertsan, U. T. Bornscheuer, and A. H. Kittikun, "Synthesis of 2-monoglycerides by alcoholysis of palm oil and tuna oil using immobilized lipases," European Journal of Lipid Science \& Technology, vol. 105, no. 2, pp. 68-73, 2010.

[23] T. Yamane, S. T. Kang, K. Kawahara, and Y. Koizumi, "Highyield diacylglycerol formation by solid-phase enzymatic glycerolysis of hydrogenated beef tallow," Journal of the American Oil Chemists' Society, vol. 71, no. 3, pp. 339-342, 1994.

[24] W. Wu, G. Zhang, R. Wang et al., "Enzymatic synthesis of glycerol monolaurate with high purity," Fine Chemicals, vol. 33, no. 8, pp. 909-914, 2016. 

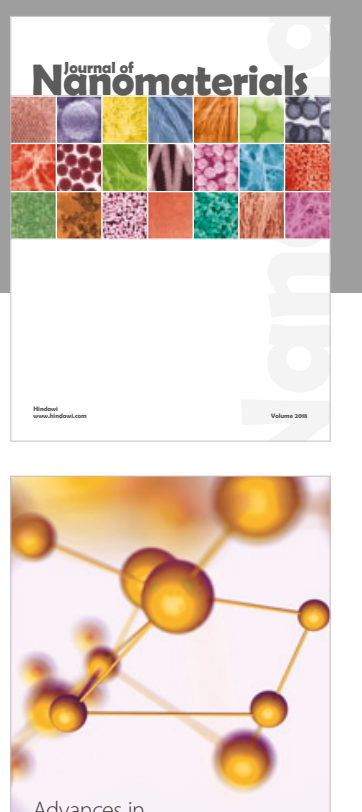

Physical Chemistry
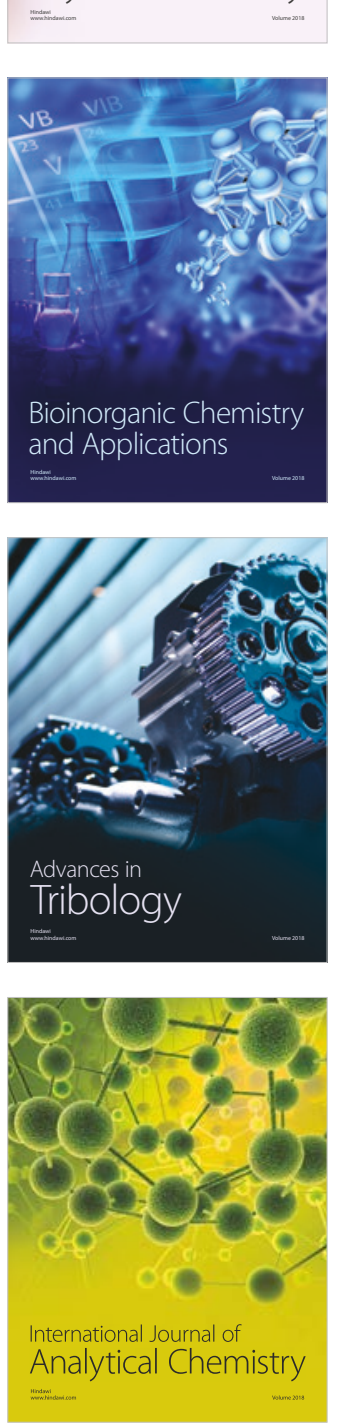

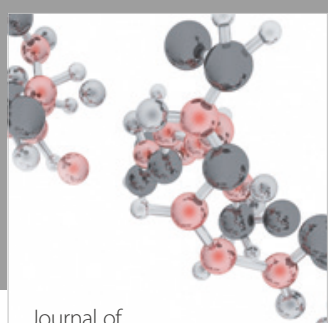

Analytical Methods

in Chemistry

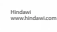

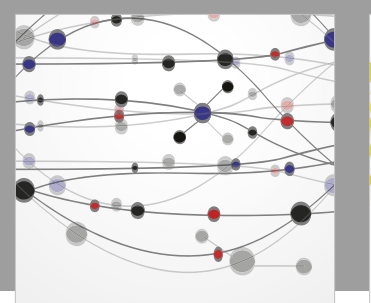

The Scientific World Journal

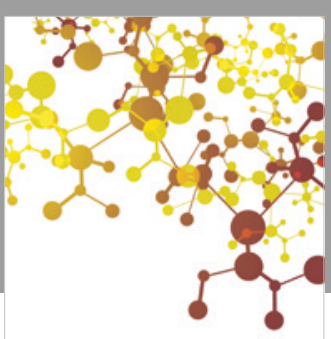

Journal of

Applied Chemistry
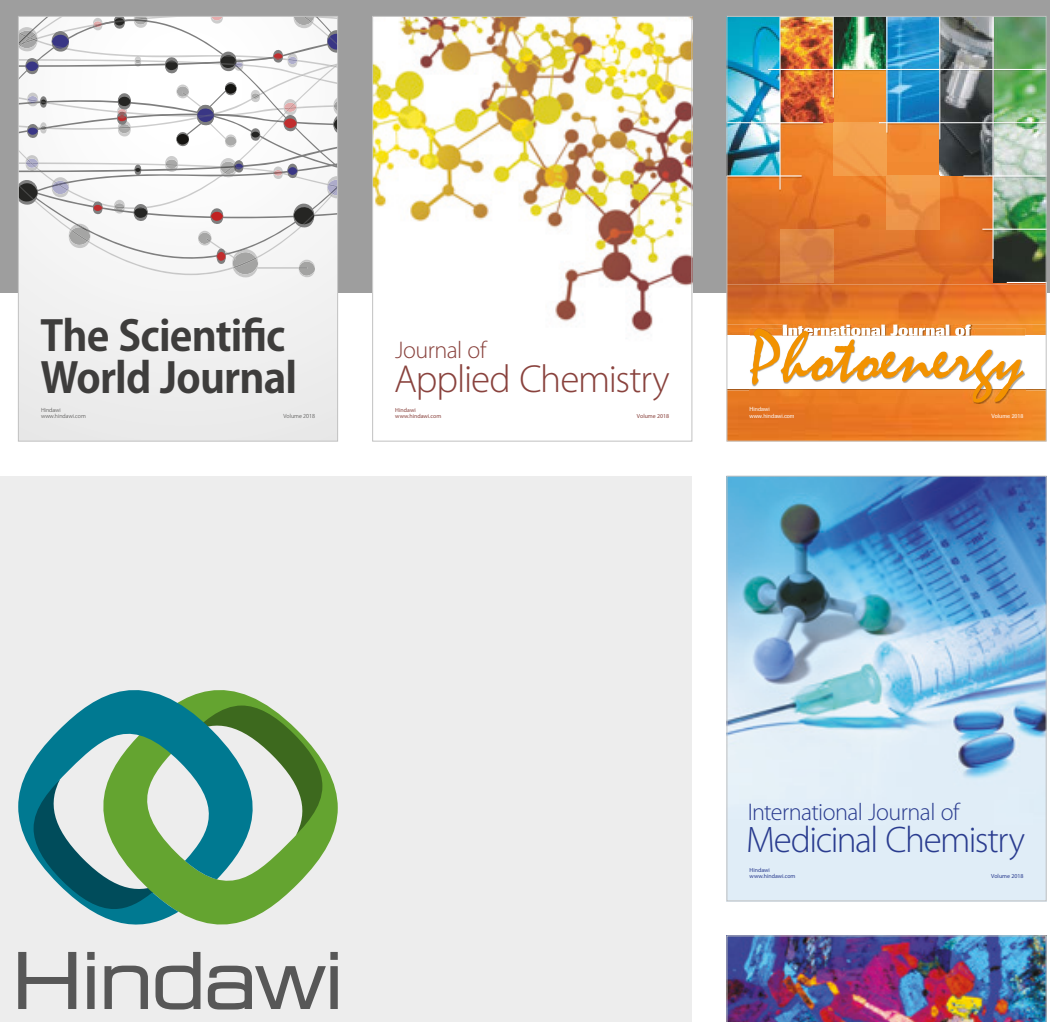

Submit your manuscripts at

www.hindawi.com
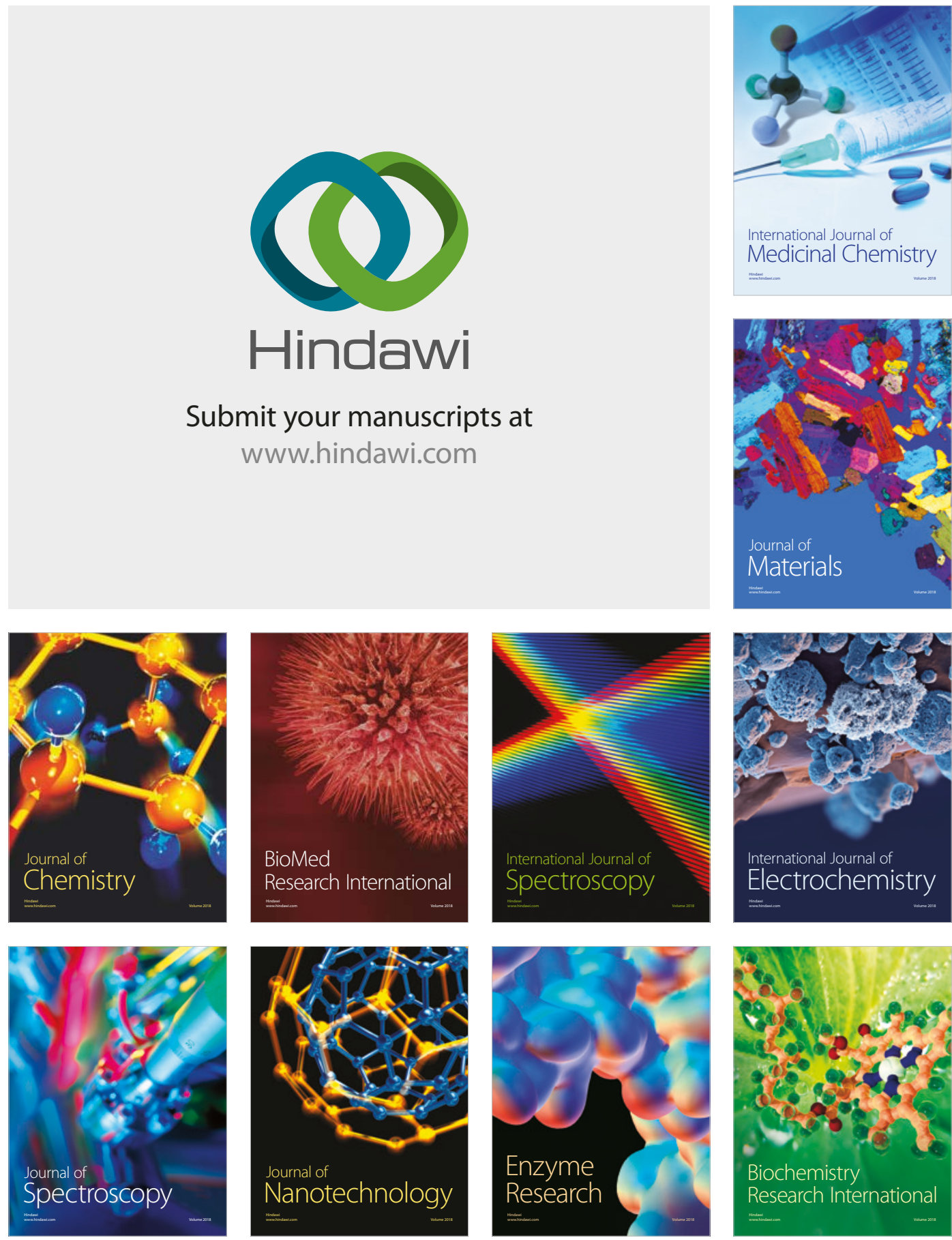
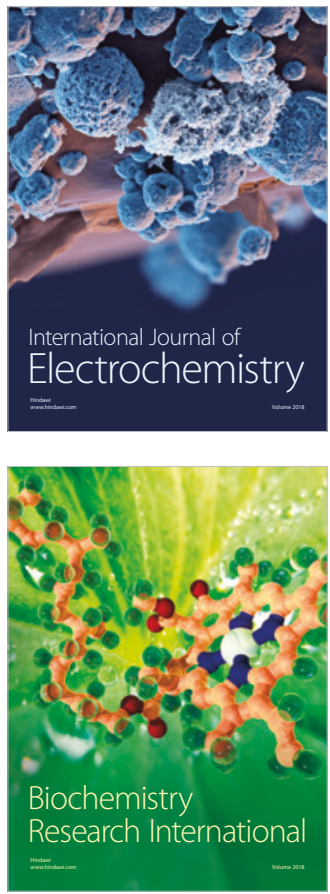